\title{
Beiträge zur Kenntnis der Leberiunktionsprüfung.
}

\author{
III. Mitteilung.
}

Über die Chromodiagnostik der Leber.

Von

Tōru Oka.

(洞) 通)

(Aus der medizinischen Klinik von Prof. T. Kumagai, Tohoku Universität zu Sendai.)

Die Anwendung des Farbstoffes zum Zweck der Leberfunktionsprü- , fung geht auf Rowntree, Hurwitz und Bloomfield ${ }^{1)}$ zurück, die 1918 zum ersten Mal Phenoltetrachlorphtalein benutzten. Dabei ergab sich, dass, wenn man $400 \mathrm{mg}$ Farbstoff intravenös einspritzt, bei Normalen 35$55 \%$ Farbstoff in den ersten 48 Stunden im Kot wiedererscheint, während die Ausscheidungsmenge bei Leberkranken bedeutend geringer ist. Unabhängig von der oben erwähnten Arbeit hat Roch ${ }^{2}$ festgestellt, dass, wenn eine kleine Menge Methylenblau per os gegeben wird, es bei Normalen fast gar nicht in Harn erscheint, während bei Leberkranken der Harn dentlich blau gefärbt wird. Rosenthal und Falkenha use $n^{33}$ haben eine Methode ausgearbeitet, nach welcher nach subkutaner Einspritzung von 5 ccm von 2\% Methylenblaulösung das Erscheinen des Farbstoffes in der Galle mittelst der Duodenalsonde geprüft wird. Bei Lebergesunden wird das Methylenblau nach 60-95 Minuten, bei Leberkranken nach 15-30 Minuten ausgeschieden; die beschleunigte Ausscheidung schrieben sie einer abnormen Durchlüssigkeit der erkrankten Leberzellen zu. Lepeh ne $\mathrm{e}^{4)}$ hat Funktionsprüfung mit intravenöser Injektion von $2 \mathrm{~cm}$ von $2 \%$ Indigokarminlösung vorgenommen. Bei Lebergesunden zeigte sich eine grüne

1) Rowntree, Hurwitzu. Bloomfield, zit. nach Aaron, Beck u. Schneide r, Journ. of Amer. Med. Ass., 1921, 77, 1631.

2) Roch, zit. nach Rosenthal und Falkenhausen (3).

3) Rosenthal u. Falkenhausen, Berl. k]. Wochenschr., 1921, 58, 1293.

4) Lepehne, Münch. med. Wochschr., 1922, 69, 342. 
Verfärbung der Duodenalgalle nach durchschnittlich 35 Minuten, bei Leberkranken wurde eine Ausscheidung des Indigokarmins sehr verzögert. Hesse und Wörner ${ }^{5)}$ verfolgten die Lepehne'sche Methode weiter und stellten fest, das die Ausscheidung bei Gesunden schon nach 25-60 Minuten stattfindet, während bei Kranken 30-130 Minuten dazu nötig waren. Sie haben im grossen und ganzen diese Methode als zuverlässig anerkannt und als Merkmal empfohlen, um den Grad der Leberstörung zu erkennen. Aber Lepehne selbst wollte sich noch nicht ganz darauf verlassen, weil

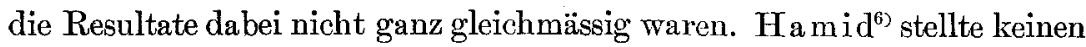
zeitlichen Unterschied bei der Rosenth a l-Falkenh a u sen'schen Methode zwischen Leberkranken und Lebergesunden fest. Ausserdem scheint Methylenblau durchaus kein richtiges Mittel für die Leberfunktionsprüfung zu sein, weil nach dem Studium von Saxl und Scherf ${ }^{7)}$ Methylenblau sehr oft auch aus der Magenschleimhaut ausgeschieden wird.

Die Ursache der Verschiedenheit der Versuchsresultate in Bezug auf die Chromodiagnostik der Leber kommt meines Erachtens von der Unklarheit über den Ausscheidungsvorgang des Farbstoffes in der Leber und von der Schwierigkeit der Auswahl des passenden Farbstoffes. Russel und Weil ${ }^{87}$ haben auf Grund des Experimentes bei Meerschweinchen drei Arten Farbstoffe unterschieden; a. Diejenigen Farbstoffe, welche nur aus der Leber ausgeschieden werden: Kongorot, Neutralrot, Safranin, Methylenblau, Biebrich Scarlet, Benzazurin und Oxaminviolett; b. Die Farbstoffe, welche nicht aus der Leber ausgeschieden werden: Rosanilin, Pyronin, Trypanrot, Orange G, Eosin, Indigokarmin, Azur, Kongokorinth u.a.; c. Die Farbstoffe, welche aus der Leber einmal ausgeschieden, ein andermal aber nicht ausgeschieden werden: Bordeaux COV, Kongornbin, Azoblau u.a. Die zuletzt genannten Farbstoffe kommen immer in der Galle vor, wenn die Leber beschädigt ist; deshalb werden sie als geeignet zur Leberfunktionsprüfung bezeichnet. Kiy on $\mathrm{o}^{9)}$ wollte aber diesem Experimente nicht völlig Glauben schenken, da er meinte, es gebe manche Farbstoffe unter a, deren Ausscheidung aus der Leber bezweifelt wird und umgekehrt unter b manche Farbstoffe, deren Ausscheidung aus der Leber wohlbekaunt ist. Er schloss daraus, dass man die Behauptungen Russsl's und Weil's nur mit Bedenken annehmen dürfe.

5) Hesse u. Wörner, Kl. Wochenschr, 1922, l, 1156.

6) Ha mid, Kl. Wochenschr., 1922, 1, 2332.

7) Saxl u. Scherf, Wien. kl. Wochenschr., 1922, 35, 128.

8) Russel u. Weil, Journ. of Amer. Med. Ass., 1917, 69, 521.

9) Kiyono, Die gegenwältigen Zustïnde des Studiums der Vitalfürbung (jap.), Tokyo-K yoto $1920,27,60$. 
Früher schon hatte Höber ${ }^{103}$ vom histologischen Standpunkt aus behauptet: wenig bzw. nicht kolloidaler Farbstoff wird von den Nierenzellen leicht aufgenommen, und der von den Nierenzellen nicht oder schwer aufzunehmende Farbstoff ist suspensionskolloidal. Die Leber vom Frosch ist nicht befähigt, besonders hoch kolloidalen Farbstoff zu eliminieren. Ferner untersuchte Möllendor $\mathrm{f}^{11)}$ an mit Farbstoff eingespritzten Kaninchen dessen Übergehen in die Galle und den Harn und gab der Höber'schen Meinung recht. Er erklärte weiter, dass die Ausscheidung der Farbstoffe aus der Niere wesentlich von der Dispersität der Farbstoffe beeinflusst wird. Je stärker die Dispersität ist, desto leichter ist die Ausscheidung, dagegen je bedeutender der Kolloidzustand, desto schwerer die Ausscheidung. Das soll mehr von der Leber als von der Niere gelten, nämlich hoch kolloidale Farbstoffe sollen nur mit grcsser Schwierigkeit aus der Leber ausgeschieden werden. Tada ${ }^{12)}$ berichtete, dass bei Hunden der Farbstoff mit wenig Diffusionsfähigkeit besonders aus der Leber ausgeschieden wird, während manche Farbstofle mit grosser Diffusionsfähigkeit hauptsächlich auch aus der Leber ausgeschieden werden. Danach glaubte er, dass der Ausscheidungsvorgang sich nicht einfach nach dem physikalischen Gesetz richtet, sondern mit der eigenartigen Auswahlfähigkeit der Leber und der Niere gegen Farbstoffe in engem Zusammenhang steht.

Wenn man bedenkt, wie wichtig und bedeutungsvoll der Farbstoff für die Leberfunktionsprüfung werden kann, so wird es eine lohnende Arbeit sein, die Farbstoffe und ihren Ausscheidungsvorgang eingehend zu untersuchen. Das ist der Grund, warum ich mich zuerst mit folgenden Versuchen beschäftigt habe.

\section{Methodik.}

Es wurde bei 31 Hunden nach $\mathrm{Pawl} / \mathrm{w}^{13}$ Gallenblasenfistel angelegt, um die Galle zu entnehmen, und der Harn wurde durch Harnkatheter oder bei dem zum Harnkatheter ungeeigneten Hunde durch Blasenfistel entnommen. Dann habe ich 29 Arten Farbstoffe ausgewïhlt und bei Hunden je $0,1 \mathrm{ccm}$ ihrer 0,5\% Lösung pro kilo intravenös eingespritzt. Danach wurden die Galle und der Harn regelmüssig zu bestimmten Zeiten entnommen und ihr Farbstoffgehalt so lange gemessen, bis der Farbstoff endlich sowohl im Harn wie auch in der Galle unerkennbar wurde. Die sümtlicken Zahlen wurden addiert, damit man sehen kann, wieviel Prozent yon dem eingespritzten Farbstoff in die Galle resp. den Harn übergegangen war. Für die Messung des Farbstoffes wurden zwei Reagenzgläser derselben

10) Höber, Biochem. Zeitschr. 1908, 11, 105; 1909, 20, 56.

11) Möllendorf, Zeitschr. f. allg. Physiol., 1918, 17, 125.

12) Tada, Nihon-Biseibutsugaku-Zasshi, 1923, 17, 63I, (jap.)

13) Pawlow, Tigerstedt's Handbuch d. physiol. Methodik, Leipzig 1911, Bd. $\mathrm{II}_{1}, 180$. 
Grösse genommen. In das eine kam eine bestimmte Menge des Harns oder der Galle nit dem zu messenden Farbstoffe; das wurde dann mit destilliertem Wasser allmählich verdiinnt, sodass man dabei erkennen konnte, bei wievielfacher Verdünnung des betreffenden Materials es die gleiche Farbe wie die Standardlösung bekam. In das andere kam als Standardlösung 0,0005\% Farbstofflösung mit derselben Menge Galle oder Harn wie die des Untersuchungsmaterials. Die beiden Reagenzröhrchen wurden in einen $\mathrm{K}_{\circ}$ mparator gesteckt und verglichen. In solcher Weise kann man feststellen, eine wievielfache Verdünnung von dern zu untersuchenden Material der Standardlösung, der 0,0005\% Farbstoffösung, entspricht; die Umrechnung des Farbstoffgehaltes des Untersuchungsmaterials ist nicht schwer. Das Vergleichen der Farben ist bei Harn sehr leicht und genau, aber bei der Galle ist es wegen der allmählichen Veränderung des Farbentons der Galle selbst ziemlich schwer. Und weil der Farbstoffgehalt unter 0,001\% in der Galle unmöglich zu messen ist, so ist der sogenannte Gehalt keineswegs von absolutem, sondern nur relativem Wert.

Die Organe der Ausscheidung der Farbstoffe sind nicht auf Leber und Niere beschränkt; Ehrlich ${ }^{14)}$ nannte ausser diesen beiden den Darm als Hauptausscheidungsort des Farbstoffes; Saxl und Scherf wiesen nach, dass der Magen aucb Ausscheidung des Methylenblaus übernimmt. Weil aber die Ausscheidung aus Leber und Niere immerhin die Hauptsache ist, so lasse ich hier die der übrigen Organe ausser Betracht.

Dann stellte ich die Untersuchung der sogenannten physikochemischen Eigenschaften der Farbstoffe an, damit ich sehen konnte, in welchem Zusammenhang solche Eigenschaften und ihr Ausscheidungsvorgang stehen. Bei der Entscheidung, ob die Farbstoffe Vitalfürbung verursachen oder nicht, habe ich mich nach Ki yo no gerichtet.

Die chemische Einteilung der in Betracht kommenden Farbstoffe ist nach den Farbstofftabellen von Schultz $\mathbf{z}^{15}$ ) angegeben. Die Permeabilität des Farbstoffes wurde in folgender Weise verglichen: es wurde ein Kollodiumsack bereitet, darein wurde $1 \mathrm{ccm} 0,5 \%$ Farbstoffösung und je $1 \mathrm{ccm}$ Aq. dest. N/50 Salzsäure, N/50 Natronlauge oder Rinderserum getan, dieser Sack wurde dann in ein gläsernes Gefäss mit $30 \mathrm{ccm}$ Aq. dest. gebracht. Nach einer Stunde wurde die Farbstoffkonzentration des umgebenden Wassers gemessen, daraus ergibt sich die durchgegangene Farbstoffmenge.

Um die Fällbarkeit der Farbstofflösung durch die Salzionen zu untersuchen, gebrauchte ich Kochsalz als einwertiges Kation, Calciumchlorid als zweiwertiges Kation und Natriumsulfat als zweiwertiges Anion, und zwar in folgender Weise: zuerst wurde je eine Normallösung vorbereitet, nämlich bei Kochsalz $58,5 \mathrm{~g} / \mathrm{dl}$, bei Calciunchlorid $55,5 \mathrm{~g} / \mathrm{dl}$, bei Natriumsulfat $66,03 \mathrm{~g} / \mathrm{dl}$; das bildete die erste Reihe der Reagenzgläser. Dann kam die weite Reibe, das sind die obengenannten, nur zweifach verdünnten Lösungen, nämlich $\frac{1}{2}$ Normallösungen; dann die dritte Reihe mit $\frac{1}{4}$ Normallösungen u.s.w.; je weiter, desto dïnner, sodass die zehnte Reihe 0,001 Normallösungen ist. Die Menge war bei allen Gläsern gleichmüssig $2 \mathrm{ccm}$, und als alles fertig war, wurde jede Lösung mit $2 \mathrm{ccm}$ der $0,1 \%$ Farbstoffösung gemischt. Nach Verlauf von 24 Stunden wurde notiert, bis zu welcher Reibe der Reagenzgläser ein Niederschlag stattgefunden hatte.

Zur Feststellung der Oberflächenspannung wurde die Tropfenzahl vermittelst eines Stalagmometers gezählt. Um das Tyndall'sche Phänomen feststellen zu können, habe ich vermittelst des Ultramikroskops die Menge des Ultramikrons beobachtet, dann habe ich weiter seine Kataphorese untersucht und zwar folgendermassen: Fin Stron von 25 Volt wurde in die Farbstofflösung eingeleitet und die Verschiebung des Vltramikrons beobachtet.

14) Ehrlich, zit. nach Höber (10).

15) Schultz, Farbstoff-Tabellen, 6. Aufl., Berlin 1923. 
Wenn es sich durch den elektrischen Strom nach dem positiven Pol schiebt, (z.B. in dem Gesichtsfeld nach rechts) und bei veränderter Richtung des Stromes nach der anderen Seite (in dem Gesichtsfeld nach links), so ist es ein negativ geladenes Ultramikron. Ebenso ist das Ultramikron, wenn es sich durch eingeleiteten Strom nach dem negativen Pol verschiebt (z.B. in dem Gesichtsfeld nach links) und bei veränderter Richtung des elektrischen Stromes dementsprechend nach rechts im GesichtsfeId, positiv geladen. Dagegen ist das Ultramikron, das durch den eingeleiteten elektrischen Stron sich nach dem positiven Pol verschiebt und trotz inzwischen veründerter Stromrichtung doch in derselben Richtugg verharrt, ein plus-minus geladenes Ultranikron und wurde mit "nach beiden Polen" notiert.

\section{Ergebnisse.}

Die Ergebnisse unserer Versuche mit 29 repräsentativen Farbstoffen sind übersichtshalber in einer Tafel mitgeteilt. Dabei wurden diejenigen Farbstoffe, die, in den Tierkörper gebracht, Vitalfärbung hervorrufen, wegen ihrer Ungeeignetheit für unseren Zweck nicht untersucht, aber manche Arten, die von früheren Antoren in der Literatur angewendet wurden, mit aufgenommen.

Man kann die sämtlichen Farbstoffe nach der Art und Weise ihrer Ausscheidung in folgende drei Gruppen einteilen: 1. Diejenigen Farbstoffe, die ausschliesslich durch die Leber ausgeschieden werden, nämlich Kongorot, Kongokorinth G., Azoblau, Kongorubin A. und Anilinblau; 2. Diejenigen Farbstoffe, deren Hauptteil aus der Leber ausgeschieden wird, während eine kleine Menge davon zugleich aus der Niere ausgeschieden wird, nämlich Bordeaux R, Azorubin, Azokarmin, Erythrosin pur., Phloxinrot P., Phloxinrot NBB, Eosin A, ausserdem gehören dazu die meisten basischen Farbstoffe; 3. Diejenigen Farbstoffe, deren Hauptteil aus der Niere ausgeschieden wird, während eine kleine Menge auch aus der Leber ausgeschieden wird, nämlich Ponceau P.R., Indigokarmin, Coccin 2 B., Chromotrop R., Fuchsin S., Phenolsulphonphthalcin.

Woher kommen solche Unterschiede in der Ausscheidung des eingespritzten Farbstoffes? Das Problem kann entweder chemisch oder physikalisch-chemisch erwogen werden. Man kann die Frage wie folgt formulieren :

1. Ob die Farbstoffausscheidung nicht von dessen chemischer Konstitution abhängig ist? Dies ist nicht wabrscheinlich, was man schon daran sieht, dass unter den Xanthonfarbstoffen Phenolsulfonphthalein hauptsächlich aus der Niere ausgeschieden wird, während Eosin, Erythrosin und Phloxin hauptsächlich aus der Leber, und von der Triphenylmethangruppe Fuchsin A sehr spärlich aus dem Harn, dagegen Süurefuchsin in Menge mit dem Harn herauskommt. 
2. Beeinflussen die Reaktion des Farbstoffes und die Vitalfärbungsfähigkeit die Ausscheidung und wie? Was die basischen Farbstoffe betrifft, so wird Pyronin z.B. durch Injektion von $0,1 \mathrm{ccm}$ pro kilo fast nicht ausgeschieden, und auch die Ausscheidung der anderen verwandten Farbstoffe, sei es nun aus der Leber oder aus der Niere, ist im Vergleich zu den sauren Farbstoffen im allgemeinen bedeutend geringer. Als Grund dieser Erscheinung der basischen Farbstoffe kann man erstens ihre starke Verbindungskraft mit den Körperzellen, zweitens Ausscheidung als unsichtbare Leukobase und drittens Ausscheidung aus dem Magen wie bei Methylenblau nach Versuchen von Saxl und Scherf nennen. Man darf aber dabei nicht vergessen, dass, obwohl die Ausscheidung der basischen Farbstoffe als ganzes unbedeutend ist, doch in die Galle bei weitem mehr austritt als in den Harn, nämlich bei Neutralrot 23\% in die Galle und 4,4\% in den Harn; bei Safranin $37 \%$ in die Galle und $1 \%$ in den Harn u.s.w. Von den sauren Farbstoffen werden die einen hauptsächlich aus der Leber, die anderen aber hauptsächlich aus der Niere ausgeschieden. Auf diesen Punkt werden wir später noch näher eingehen.

Die Farbstoffe mit vitaler Färbungsfähigkeit, die wir angewendet haben, sind Nigrosin, Trypanrot, Trypanblau und Lithionkarmin. Sie werden in dieser Beziehung noch bei weitem weniger ansgeschieden; bei Trypanblau, Trypanrot und Nigrosin kommt eine winzige Menge heraus, dagegen allein bei Lithionkarmin verhätnismässig mehr, doch ist auch da nur 15\% im Harn zu finden. Diese Sache werden wir später noch auseinandersetzen.

3. Was für einen Einfluss übt die Dispersität der Farbstoffösung auf die Ausscheidung? Nach der Dispersität kann man die Farbstoffe, wie man aus der Tafel sehen kann, ungefähr folgendermassen aneinander reihen: Kongorot, Kongokorinth G., Azoblau, Kongorubin A., Anilinblau, Nigrosin, Trypanblau, Trypanrot, Lithionkarmin, Bordeaux R., Ponceau P.R., Azorubin S., Azokarmin, Indigokarmin, Erythrosin pur., Coccin 2B., Phloxinrot NBB., Eosin A., Phloxinrot P., Chromotrop P., Fuchsin S., Phenolsulphonphthalein, und bei den basischen Farbstoffen : Nilblau, Neutralrot, Pyronin, Methylenblau, Safranin, Fuchsin A., Azur I. Man sieht auch in der Tafel, dass diejenigen Farbstoffe, deren Permeabilität durch die Kollodiummenbran schwach ist, die besonders durch zweiwertiges Kation leicht gefälltt werden und deren Tyndall'sches Phänomen ausserdem noch bedeutend ist, nämlich Kongorot, Kongokorinth, Azoblau, Kongorubin, Anilinblau u.a. hauptsächlich aus der Leber ausgeschieden werden, während sie durch die Niere gar nicht oder nur in ganz geringer 
Ausscheidung der Farbstoffe und

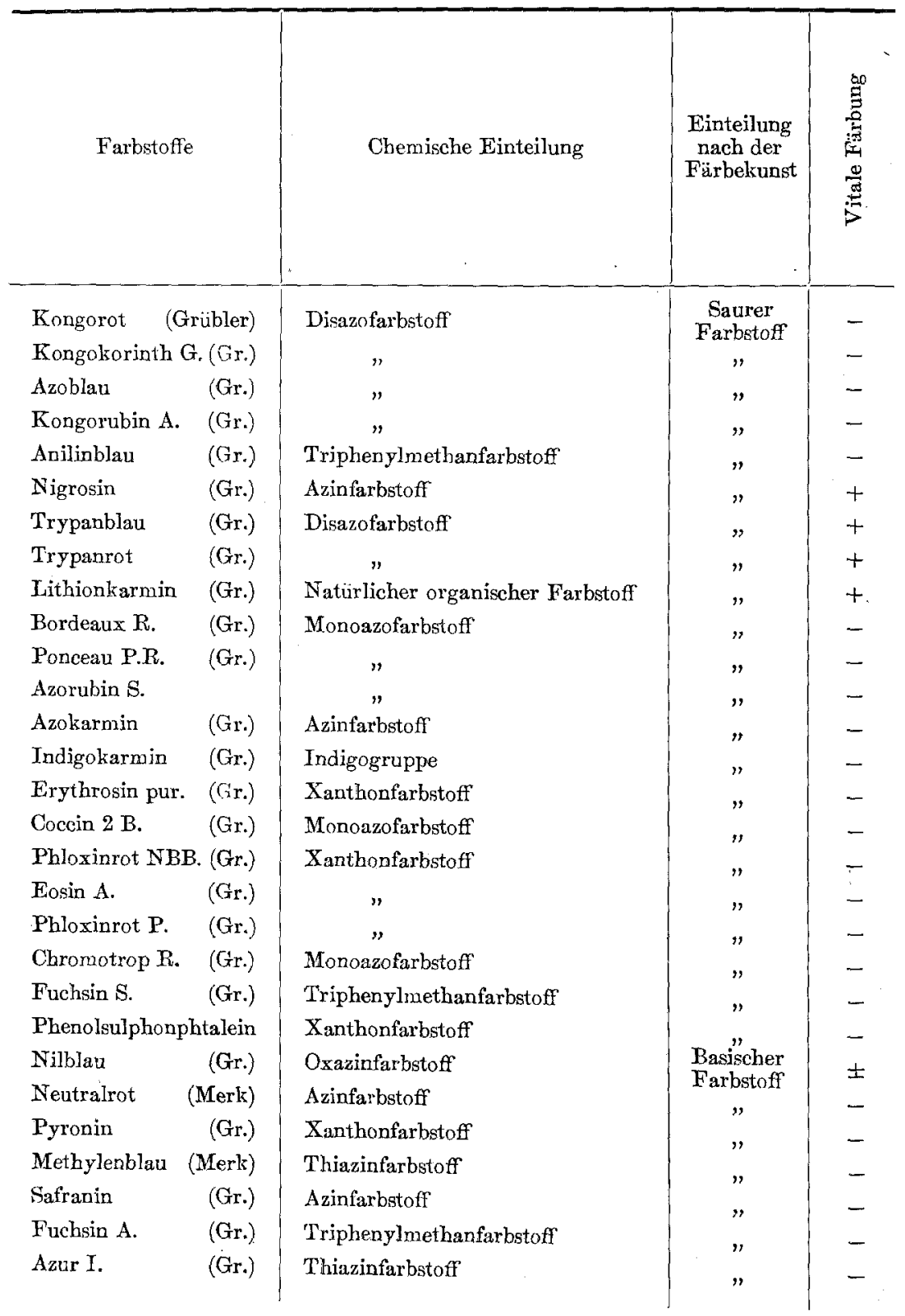


fel

ihre physikochemischen Eigenschaften

\begin{tabular}{|c|c|c|c|c|c|c|c|c|c|c|c|c|}
\hline \multirow{2}{*}{\multicolumn{4}{|c|}{$\begin{array}{l}\text { Permeabilität der Farb- } \\
\text { stoffe durch die } \\
\text { Kollodiummembran } \\
\text { (durchgetretene Farb- } \\
\text { stoffmenge in } 1 \text { St. \%) } \\
\text { Hinzugesetzte Flüssigkeit }\end{array}$}} & \multirow{2}{*}{\multicolumn{3}{|c|}{$\begin{array}{l}\text { Füllbarkeit } \\
\text { durch } \\
\text { Salzion }\end{array}$}} & \multirow{3}{*}{ 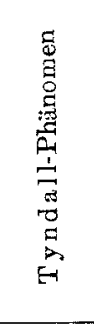 } & \multicolumn{2}{|c|}{$\begin{array}{c}\text { Tropfenzahl } \\
\text { der Farb- } \\
\text { stofflösung } \\
\text { bei } 18^{\circ} \mathrm{C}\end{array}$} & \multirow{3}{*}{ 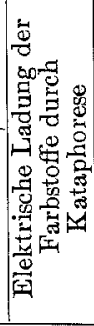 } & \multirow{2}{*}{\multicolumn{2}{|c|}{$\begin{array}{l}\text { Ausscheidung } \\
\text { der Farbstoffe } \\
\text { von } 0,5 \%, \\
\text { von denen je } \\
0,1 \text { ccm pro } \\
\text { kilo intrave- } \\
\text { nös injiziert }\end{array}$}} \\
\hline & & & & & & & & \multirow{2}{*}{ 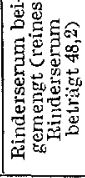 } & \multirow{2}{*}{ 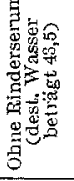 } & & & \\
\hline 安要 & 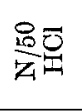 & 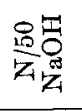 & 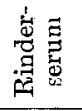 & 茫 & 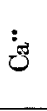 & 㐔 & & & & & 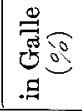 & 䮖 \\
\hline - & - & Spur & - & 2 & 10 & - & & 46,0 & 44,7 & - & $\$ 2,0$ & - \\
\hline- & - & 0,45 & - & 5 & 10 & - & $"$ & 46,8 & 43,0 & - & 31,0 & - \\
\hline 0,75 & - & 0,75 & - & 2 & 10 & 10 & $"$ & 47,2 & 43,1 & - & 64,0 & - \\
\hline 3,0 & Spur & 6,5 & - & 10 & 10 & 1 & $"$ & 47,1 & 43,0 & - & 89,9 & Spur \\
\hline 6,5 & 65 & 6,5 & - & - & & - & " & 46,5 & 43,0 & 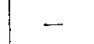 & + & - \\
\hline 4,5 & 1,5 & 7,5 & Spur & - & 6 & - & & 46,6 & 43,1 & - & 3,0 & - \\
\hline 4,5 & 10,5 & 10,5 & 0,75 & 2 & 7 & - & & 45,6 & 43,0 & \pm & + & Spur \\
\hline 10,5 & 15,0 & 7,5 & 3,0 & 2 & 6 & - & & 48,4 & 43,0 & $\perp$ & Spur & Spur \\
\hline 10,5 & 3 & 19,5 & 15,0 & 3 & 7 & - & $"$ & 49,9 & 50,0 & \pm & - & 15,0 \\
\hline 15,0 & 22 & 22,5 & 1,0 & - & 4 & . & $"$ & 47,5 & 48,0 & - & 49,0 & 18,0 \\
\hline 21,0 & 27,0 & 27,0 & 10,5 & - & 2 & - & wenig & 48,0 & 45,0 & \pm & 37,0 & 41,0 \\
\hline 25,5 & 25 & 25,5 & 5 & - & 1 & - & $"$ & 47,4 & $6, z$ & & 3,0 & 6,0 \\
\hline 25,5 & 36,0 & 36,0 & 18,0 & 3 & 4 & - & " & 48,3 & 43,8 & - & 28,0 & 12,0 \\
\hline 25,5 & 25,5 & 15,0 & 25,5 & 1 & 2 & - & $"$ & 47,2 & 43,2 & 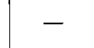 & 36,0 & 39,0 \\
\hline $\mathbf{2 5}, 0$ & - & 25,0 & 3,0 & - & 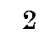 & - & Spur & 47,9 & 43,1 & - & 97,6 & 1,9 \\
\hline 27,0 & 27,0 & 27,0 & 27,0 & - & - & - & $"$ & 46,8 & 43,1 & \pm & Spur & 41,0 \\
\hline 27,0 & - & 27,0 &, 0 & - & $\overline{-1}$ & 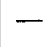 & " & 46,5 & 43,7 & 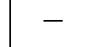 & 85,0 & - \\
\hline 27,0 & - & 27,0 & 7,5 & - & - & - & $"$ & 46,4 & 44,0 & - & 95,0 & 1,5 \\
\hline 28,5 & 一 & 28,5 & Spur & - & - & - & $"$ & 46,4 & 43, & . & 84,0 & - \\
\hline 30,0 & 30,0 & 48,0 & 33,0 & - & 一 & - & $"$ & 47,3 & 44,1 & \pm & 44,0 & 48,0 \\
\hline 34,5 & 33 & 34,5 & 34,5 & - & - & - & 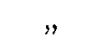 & 47,3 & 42,8 & $I$ & 9,0 & 87,0 \\
\hline 40,5 & 40, & 45,0 & 40,5 & - & - & - & & 46,2 & 43,6 & + & 8,7 & 88,0 \\
\hline 10,5 & 7 & - & 0 & 4 & 5 & 5 & & 53,2 & 61,0 & + & + & - \\
\hline 15,0 & 18 , & - & 1,5 & 6 & 5 & 7 & $"$ & 51,0 & 46,2 & + & 23,0 & 4,4 \\
\hline 16,5 & 22, & - & 3,0 & 7 & 4 & 9 & $"$ & 46,5 & 44,0 & + & - & - \\
\hline 21,0 & 24,0 & 18,0 & 8,0 & 2 & - & - & wenig & 48,6 & 44,0 & + & 12,0 & 6,0 \\
\hline 24,0 & 27,0 & 6,5 & 4,5 & 2 & - & - & & 48,6 & 45,0 & + & 37,0 & 1,0 \\
\hline 24,0 & 24 , & 8,0 & 3,7 & 5 & 5 & 7 & & 51,0 & 56,1 & + & 14,0 & 12,0 \\
\hline 27,0 & 30,0 & Spur & 4,5 & - & - & - & Spur & 48,0 & 43,0 & + & 17,0 & 9,8 \\
\hline
\end{tabular}


Menge herauskommen.

Anilinblau scheint eine Ausnahme zu bilden. Dieser Farbstoff wird in der Galle als Lenkobase ausgeschieden, im Harn gar nicht. Bei Zusatz von Salzsäure verwandelt sich die Leukobase in blaue Farbe, aber zugleich wird Bilirubin auch in grünes Biliverdin oxydiert, sodass die quantitative Messung der ausgeschiedenen Farbstoffe unmöglich ist.

Daraus kann man sehen, dass die Farbstoffe mit hochgradigem Kolloidzustand bei Hunden fast nur durch die Leber ausgeschieden werden. Die zum Semikolloid gehörigen Farbstoffe werden sowohl durch Leber wie auch durch Niere in sehr geringen Masse ausgeschieden. So sind z.B. von der sauren Farbstoffreihe Trypanrot, Trypanblau und Lithionkarmin zu neunen, die aber alle vitaler Färbung fähig sind. Von den basischen Farbstoffen gehört dazu Nilblau.

Andererseits sind diejenigen Farbstoffe, deren Permeabiltät durch die Kollodiummembran stark ist, von denen also in 1 Stunde mehr als 15\% diffundiert wird und die durch Salzion schwer gefüllt werden und deren Tyndall'sches Phänomen unbedeutend ist, mit anderen Worten diejenigen Farbstoffe, die mit der echten Lösung verwandt sind, werden teils wesentlich aus der Niere, teils wesentlich aus der Leber ausgeschieden; zu ihnen gehören Phenolphthalein, Fuchsin S., Chromotrop, Cocein 2B., Indigokarmin und Poncau P. R. und zu diesen gehören Phloxinrot P., Phloxinrot NBB., Erythrosin, Eosin, Azorubin S., Azokarmin und Bordeaux.

Was kann der Grund solches Unterschiedes sein? Bethe ${ }^{16)}$, Rhode $e^{17}$ und Pohle ${ }^{18}$ meinten: die Aufnahme, Vitalfärbung und Resorption saurer und basischer Farbstoffe sind abhängig von der Menge der in den betreffenden Zellen und ihrer Umgebung vorhandenen freien $\mathrm{H}^{\cdot}$ oder $\mathrm{OH}^{\prime}$, indem die der sauren Farbstoffe durch $\mathrm{H}^{\prime}$ beschleunigt, durch $\mathrm{OH}^{\prime}$ aber verlangsamt wird und das Umgekehrte für basische Farbstoffe gilt. Diese Annahme kann vielleicht für die Vitalfärbung gelten, aber nicht für die Ausscheidung. In einem Versuche habe ich dem mit $30 \mathrm{ccm}$ von N/10 Salzsäure intravenös injizierten Hunde zugleich Phloxinrot injiziert und konnte dabei den Übergang des Farbstoffes in den Harn nicht feststellen, auch konnte ich durch Einführung von $10 \mathrm{~g}$ Natriumbicarbonat in die Venen und zugleich von basischem Safranin eine Zunahme der Ausscheidung in den Harn nicht feststellen.

Worin besteht der Einfluss der Säure oder des Alkalis auf die Perme-

16) Bethe, Binchem, Zeitsch., 1922, 127, 18.

17) Rhode, Pflüger's Arch., 1920, 182, 114.

18) Pohle, Deut. med. Wochenschr., 1921, 47, 1464. 
abilität des Farbstoffes durch die Kollodiummembran? Saure Farbstoffe werden in den meisten Fällen bei saurer Reaktion in ihrer Disperistät vermindert und ihr Molekül vergrössert: die Folge ist Abnahme der Permeabilität; Beispiele dafür sind Erythrosin, Eosin A., Phloxinrot; nämlich in der Azidität über Pr 5 verschwindet die Permeabilität beinahe vollständig, die genannten Farbstoffe werden fast ausschliesslich durch die Leber ausgeschieden. Basische Farbstoffe werden gleichfalls bei alkalischer Reaktion in ihrer Dispersitüt vermindert und ihr Molekül grösser, die Folge ist Störung der Permeabilität, diese Farbstoffe kommen auch mehr in die Galle als in den Harn. Den Grund, warum manche Farbstoffe durch die Leber und manche durch die Niere ausgeschieden werden, könnte man deshalb, nach dem Ergebnis des oben beschriebenen Versuches, nicht in der Reaktion der Umgebung der Zellen, wie Bethe u.a. behaupteten, vielmehr in der Reaktion des Harns oder der Galle suchen. Zu dem Zweck wurde $10 \mathrm{~g}$ Natriumbicarbonat intra venös eingeführt, um den Harn alkalisch zu machen, und dann Phloxinrot eingespritzt, trotzdem blieb der Übergang des Farbstoffes in den Harn aus. Das beweist schon, dass die Reaktion im Harn und in der Galle auf die Ausscheidung keinen besonderen Einfluss ausübt. Es ist aber möglich, dass die alkalische Reaktion im Serum die Dispersität des basischen Farbstoffes vermindert, dessen Molekül vergrössert und dadurch die Ausscheidung durch die Niere erschwert; für die sauren Farbstoffe gilt das Umgekehrte.

Ein anderer wichtiger Versuch, bei dem neben 0,5\% Farbstofflösung auch eine gleiche Menge Rinderserum in einen Kollodiumsack eingeführt wurde, hat mir gezeigt, dass die Permeabilität des Farbstoffes bedeutend gestört wurde. Nur grosse Schwankungen der Störung je nach dem Farbstoff wurden bemerkt: Phenolsulphonphthalein, Fuchsin S., Chromotrop, Coccin 2B. und Indigokarmin wurden darin verhältnismässig wenig gestört, dagegen Phloxinrot P., Erythrosin, Phloxinrot NBB., Eosin A., Azorubin S. und basische Farbstoffe bedeutend mehr. Eine Ausnahme bildet Lithionkarmin, das seine Permeabilität dadurch nur verstärkt, was vielleicht von der durch alkalische Reaktion im Serum hervorgebrachten Zunahme der Löslichkeit herrührt.

Was dabei interssant ist, ist die Tatsache, dass die Störung der Permeabilitätdes mit Serum vermengten Farbstoffes parallel zu der Fähigkeit geht, hauptsächlich ans der Galle oder hauptsächlich aus dem Harn ausgeschieden zu werden. Nämlich von der beinahe echten Lösung werden diejenigen Farbstoffe, die mit dem Serum vermengt in ihrer Permeabilität bedeutend gestört werden, nämlich, Eosin, Erythrosin, Phloxinrot, Azorubin 
S.u.a. oder basische Farbstoffe, hauptsächlich aus der Leber ausgeschieden, dagegen die Farbstoffe, die selbst mit dem Serum vermengt in ibrer Permea bilität wenig gestört werden, nämlich Phenolsulphonphthalein, Fuchsin S., Chromotrop, Coccinn 2B., Indigokarmin u.a., hauptsächlich aus der Niere.

Warum wird der Farbstoff, wenn er mit Serum vermengt ist, in seiner Permeabilität gestört, und warum kommt diese Erscheinung bei allen Farbstoffen gleichmässig vor? Ehrlich hat 1898 seine Ansicht darüber geïussert, die dahin geht, dass, was nicht aus der Niere ausgeschieden wird, entweder durch die Leber oder den Darm ausgeschieden oder durch Verbindung mit dem Bluteiweiss zur Ausscheidung überhaupt unfähig wird. Die Verminderung der Permeabilität des Farbstoffes durch Serum kann vielleicht seiner Adsorption von Serumeiweiss zuzuschreiben sein.

Was die Kataphorese der Farbstoffe anbetrifft, so habe ich festgestellt, dass sich die basischen Farbstoffe nach dem negativen Pol verschieben, d.h. positiv geladen sind, während sich bei den sogen. sauren Farbstoffen die mit hochgradigem Kolloidzustand deutlich nach dem positiven Pol verschieben, d.h. negativ geladen sind; dagegen die mit geringem Kolloidzustand sich verschieden verhalten, d.h. manche bewegen sich nach dem positiven Pol, manche undeutlich, oder gleichzeitig nach beiden Polen; diese sind wahrscheinlich amphoteren Charakters oder ganz schwache Säuren.

Es sind darunter stark negativ geladene, deren Permeabilität durch die Kollodiummembran, wenn mit dem Serum vermengt, sehr abgeschwächt wird.

Aber die Adsorptionserscheinung muss sehr komplizierten Charakters sein, so dass sie nicht einfach durch Oberflächenspannung und elektrische Ladung allein restlos erklärt werden kann. Dies kann nan daraus ersehen, dass der stalagmometrisch bestimmte Wert durch Beimengung von Serum nicht besonders beeinflusst wird. Aber soviel darf man wohl mit Sicherheit sagen: die Tatsache, dass diejenigen Farbstoffe, die, obwohl sie in echter Lösung sind, d.h. deren Permeabilität stark ist, die durch Salzionen schwer fällbar sind und deren Ty ndall'sches Phänomen schwach ist, doch hauptsächlich aus der Leber ausgeschieden werden, ist dem zuzuschreiben, dass sie nach der Einführung in den Körper durch Adsorption des Serumeiweisses in ihrer Permeabilität herabgesetzt sind, so dass sie bei der Ausscheidung aus der Niere behindert sind.

Katsura $a^{199}$ aus unserem Laboratorium, der sich mit der Resorption des Farbstoffes beschäftigt hat, kounte nachweisen, dass der Farbstoff vom

19) Katsura, Tohoku Journ. of Exp. Med., 1924, 5, 294. 
Kolloidzustand ausschliesslich vom Lymphwege resorbiert wird, dagegen der in echter Lösung durch die Blutbahn. Sein Experiment liefert uns ein glänzendes Beispiel dafür, wie viel die Resorption des Farbstoffes mit seiner physiko-chemischen Eigenschaft zu tun hat. Warum sollte man es für unmöglich halten, das auch für die Ausscheidung gelten zu lassen, was sich für die Resorption als richtig erwiesen hat? Es hat bis heute nicht an Forschern gefehlt, die zwischen der Ausscheidung der Farbstoffe und deren physikalisch-chemischen Eigenschaften einen Zusammenhang suchen wollten, aber die einen haben dabei nur einen Teil der Eigenschaften in Betracht gezogeñ, währed die anderen sich auf die Lösung der Farbstoffe als solche beschränkten. Sie versäumten dabei, der Permeabilität in dem mit dem Serum gemischten Zustand ihre Aufmerksamkeit zu schenken. Das ist die Ursache, die es ihnen so schwer gemacht hat, den Zusammenhang der Ausscheidung mit deren physikochemischen Charakter zu finden.

Das Ergebnis unseres Experimentes sei hier noch einmal kurz zusammengefasst: ob die Farbstoffe bei Hunden aus der Leber oder aus der Niere ausgeschieden werden, das hängt ausschliesslich von der Stärke der Permeabilität der betreffenden, mit Serum vermengten Farbstoffe ab, d.h. diejenigen, deren Kolloidzustand hochgradig ist, werden aus der Leber ausgeschieden, und diejenigen, die wenig kolloidale Lösung oder echte Lösung bilden, werden nur im Fall stark gestörter Permeabilität der mit Serum gemischten Lösung gleichfalls in der Hauptsache aus der Leber ausgeschieden, während die übrigen aus der Niere eliminiert werden. 